\title{
The mechanism of the paralysing action of tetramisole on Ascaris somatic muscle
}

\author{
J. ACEVES, D. ERLIJ AND R. MARTÍNEZ-MARAÑóN
}

Instituto de Salubridad y Enfermedades Tropicales and Departamento de Fisiología del Centro de Investigación y de Estudios Avanzados del Instituto Politécnico Nacional, México, D.F.

\section{Summary}

1. Tetramisole $(100 \mu \mathrm{g} / \mathrm{ml})$ paralysed live Ascaris in $3 \mathrm{~min}$.

2. Tetramisole $(10 \mu \mathrm{g} / \mathrm{ml})$ caused a sustained contraction of the isolated somatic muscles of the worm. This contraction was not blocked by curare nor by piperazine.

3. Tetramisole reduced the resting potential of Ascaris muscle from $34 \pm 4$ to $10 \pm 1 \mathrm{mV}$.

4. Tetramisole caused contraction of Ascaris muscle previously depolarized with high $\mathrm{K}^{+}$solutions. This observation suggests that tetramisole can induce a contracture that is independent of membrane depolarization.

\section{Introduction}

It has been reported that tetramisole [( \pm )-2,3,5,6-tetrahydro-6-phenylimidazo[2,1b]thiazole hydrochloride], a recently developed anthelmintic drug, is more powerful than piperazine in the treatment of nematode infestations of man and other animals (Thienpont, Vanaparijs, Raeymaekers, Vandenbert, Demon, Allewijn, Marsboom, Niemgeers, Schellekens \& Janssen, 1966 ; Chaia \& Cunha, 1968).

In the present investigation the effects of tetramisole on the mechanical and electrical activity of Ascaris somatic muscle has been examined.

\section{Methods}

Specimens of Ascaris lumbricoides were collected from pigs killed at the local slaughter house and transferred to the laboratory in Locke's solution. Segments of both female and male worms were used for electrical and mechanical recording. In most cases the $4 \mathrm{~cm}$ anterior to the genital pore were used. The worm was split open along one of the lateral lines and the gut was carefully removed.

To obtain the contraction records the preparations were vertically suspended by two sutures passing through the unsplit lateral line. One of the sutures was tied to a holder at the bottom of a glass bath the temperature of which was maintained at $38^{\circ} \mathrm{C}$, while the other suture was tied to a Grass mechanoelectrical transducer connected to a Grass polygraph.

To record the electrical activity, micropipettes filled with $3 \mathrm{M} \mathrm{KCl}$ (resistance 10 to $20 \mathrm{M} \Omega$ ) were used. The micropipettes were connected to a negative capacitance 
amplifier through $\mathrm{Ag}-\mathrm{AgCl}$ electrodes. The output of the amplifier was displayed on the screen of an oscilloscope and photographed. In these experiments the slit segment of worm was pinned out flat, cuticle side down, on a slab of balsa wood. This slab was placed in a Plexiglass chamber whose temperature was maintained at $38^{\circ} \mathrm{C}$. The microelectrodes were inserted in the muscle cell bellies (for anatomical details and nomenclature see De Bell, Del Castillo \& Sánchez, 1963). The solution used in most experiments had the following composition in mmol/1.: $\mathrm{Na}^{+}, 135 ; \mathrm{K}^{+}, 3 ; \mathrm{Ca}^{++}, 3 ; \mathrm{Mg}^{++}, 15 \cdot 7 ; \mathrm{Cl}^{-}, 175.4$ and $\mathrm{HCO}_{3}{ }^{-}, 0.8 ;$ in some experiments a solution designated as $50 \mathrm{mM} \mathrm{K}^{+}$was used; it had the composition in $\mathrm{mmol} / 1$.: sucrose, $200 ; \mathrm{K}^{+}, 50.8 ; \mathrm{CA}^{++}, 8 ; \mathrm{Mg}, 15 \cdot 7 ; \mathrm{Cl}, 31.4 ; \mathrm{SO}_{4}, 33$ and $\mathrm{HCO}_{3}{ }^{-}, 0.8$. When the animals were immersed in either of these solutions for the purpose of recording contractions, the latter were bubbled with a mixture of $95 \% \mathrm{~N}_{2}$ and $5 \% \mathrm{CO}_{2}$ throughout the experiment. The same gas mixture was bubbled through the solutions used in the experiments to record electrical activity for $\mathbf{3 0}$ min before being introduced into the Plexiglass chamber. The solution was not "gassed" while it was in the chamber.

\section{Results}

\section{Tetramisole on live Ascaris}

In agreement with the observations of Goodwin (1958) we found that live specimens of Ascaris become paralysed after $3 \mathrm{~h}$ of immersion in a solution containing piperazine $(1: 250)$. When worms were immersed in a solution of tetramisole $(100 \mu \mathrm{g} / \mathrm{ml})$ they were immobilized within $5 \mathrm{~min}$; when tetramisole $10 \mu \mathrm{g} / \mathrm{ml}$ was used they were paralysed within $30 \mathrm{~min}$. Tetramisole does not kill the worms ; the paralysed nematodes recover their motility after $24 \mathrm{~h}$ of immersion in a fresh solution.

\section{Effects of tetramisole on tension development by Ascaris somatic muscle}

The effects of tetramisole on the tension developed by Ascaris somatic muscle are illustrated in Fig. 1. A dose of acetylcholine $30 \mu \mathrm{g} / \mathrm{ml}$ was given before the
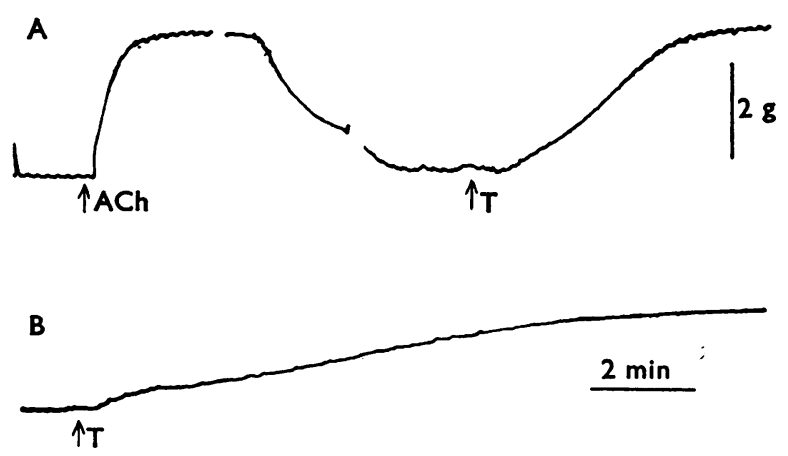

FIG. 1. Effects of tetramisole and acetylcholine on the contractile activity of Ascaris somatic muscle. A, The arrow marked ACh indicates the time when acetylcholine was added to the solution in the bath to give a concentration of $30 \mu \mathrm{g} / \mathrm{ml}$. After a steady level of tension was reached a fresh solution was introduced to the bath at the points indicated by the interrupted tracing. The arrow marked $T$ indicates the addition of tetramisole to the bath to give a concentration of $50 \mu \mathrm{g} / \mathrm{ml}$. $\mathrm{B}$, The arrow $\mathrm{T}$ indicates the addition of tetramisole to the bath to give a concentration of $4 \mu \mathrm{g} / \mathrm{ml}$. 
addition of tetramisole. This dose produced a maximum contracture. After washing out the acetylcholine, tetramisole $50 \mu \mathrm{g} / \mathrm{ml}$ initiated a sustained contracture of amplitude equal to that produced by acetylcholine. The tetramisole induced contractures continued for periods as long as $30 \mathrm{~min}$ if the drug was not washed out of the bath. The relaxation after washing was slow; it took about $10 \mathrm{~min}$ to reach half amplitude; on the other hand, the muscle was almost completely relaxed 3 min after washing out a dose of acetylcholine.

After washing out the tetramisole, the response to a second dose of the drug or to acetylcholine was depressed to about $50 \%$ of its initial value.

The threshold concentration for the tetramisole contracture was between 3 and $8 \mu \mathrm{g} / \mathrm{ml}$, and maximal responses were obtained when concentrations of $30 \mu \mathrm{g} / \mathrm{ml}$ or more were used. The main difference between the effects of doses just above threshold and those having maximal effects was their speed of action (see Fig. 1, part B).

In three instances recordings were made of preparations that included the head of the worm as described by Goodwin \& Vaughan Williams (1963). Tetramisole $30 \mu \mathrm{g} / \mathrm{ml}$ also produced a sustained contracture in these preparations.

Many results suggest that acetylcholine is the natural excitatory transmitter at the Ascaris neuromuscular junction (Del Castillo, De Mello \& Morales, 1963 ; De Bell, 1965). To test whether tetramisole acted through the liberation of acetylcholine from nerve endings, the action of tetramisole was tested while the preparation was immersed in a solution containing $1 \mathrm{mg} / \mathrm{ml} \mathrm{(+)-tubocurarine.} \mathrm{A} \mathrm{typical}$ experiment is illustrated in Fig. $2 \mathrm{~A}$ and $\mathrm{B}$. The figure shows that although the dose of curare employed was sufficient to block the effects of acetylcholine it did not suppress the response to tetramisole. Part $\mathrm{C}$ shows that a dose of piperazine

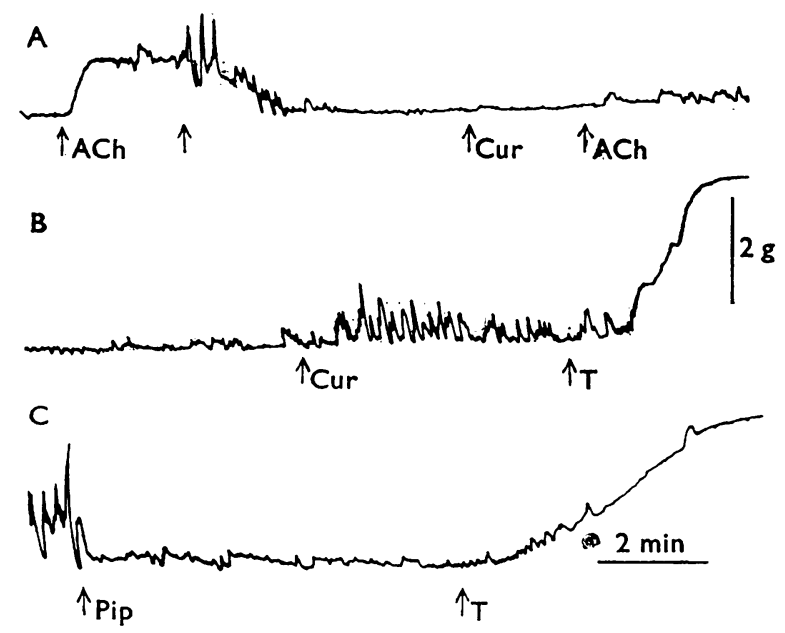

FIG. 2. Effects of tetramisole on Ascaris muscle treated with curare or piperazine. A, the preparation was exposed to ACh $20 \mu \mathrm{g} / \mathrm{ml}$ during the period marked by the first two arrows. The arrow designated Cur indicates the point when curare was added to the bath to give a concentration of $1 \mathrm{mg} / \mathrm{ml}$. Between $A$ and $B$ the bath was washed. Cur marks the reintroduction of curare to the bath and at the point indicated by the arrow $T$, tetramisole was added (final concentration $30 \mu \mathrm{g} / \mathrm{ml}$ ). Tracing $C$ shows the action of piperazine (Pip) on spontaneous activity of the muscle and at $\mathrm{T}$, tetramisole was added to the piperazine containing solution. 
of $300 \mu \mathrm{g} / \mathrm{ml}$ (base) that was sufficient markedly to depress spontaneous contractions did not block the tetramisole induced contracture.

\section{Effects of tetramisole on the electrical activity of Ascaris}

The mean resting membrane potential of sixty-two cells penetrated during the control period was $34 \pm 4 \mathrm{mV}$, inside negative. This value was calculated by arbitrarily selecting the maximum negativity recorded during interspike intervals of spontaneously active cells (twenty-nine out of the sixty-two) as the value for the resting potential.

Although it was difficult to maintain a microelectrode inside a cell during the rise in tension caused by tetramisole, satisfactory records of the time course of tetramisole action in a single cell were obtained in six instances. A typical observation is illustrated in Fig. 3. Record 3B is characteristic of the electrical activity of untreated Ascaris somatic cells (De Bell et al., 1963). At variable intervals slow depolarizations of small amiplitude occur; on these slow depolarizations a number of small potential transients are superimposed. Sometimes the amplitude of these transients is sufficient to produce a full-sized spike. Record $\mathrm{C}$ was obtained 6 min after the addition of tetramisole; the resting potential was $21 \mathrm{mV}$ and the spike frequency increased. This increased frequency could result from a higher rate of oscillation of the pacemaker region of the cell; it could also be explained if we accept that before the addition of the drug (record B) alternate oscillations resulted in action potentials propagating into the cell bellies. During the action of the drug (record C) every oscillation acting on a lower membrane potential produced a spike. Eight minutes after adding tetramisole, record D was obtained. The cell was further depolarized and no evidence of increased frequency of oscillations was seen; the rates of rise of the spike and its repolarization were markedly slowed. Ten minutes after addition of the drug the cell was silent and its membrane potential was $11 \mathrm{mV}$. During this stage of tetramisole action many cells were penetrated. None fired spontaneously and their mean membrane potential was $10 \pm 1 \cdot 1 \mathrm{mV}$ $(n=50)$.

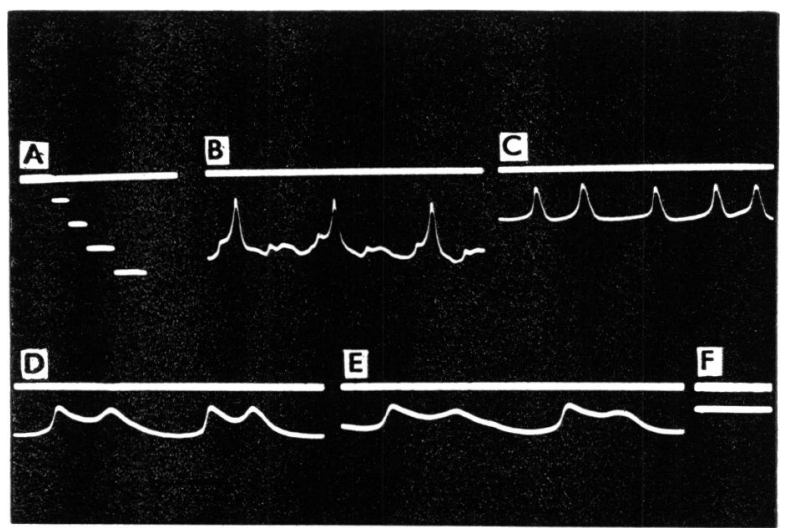

FIG. 3. Effects of tetramisole on the electrical activity of a single muscle cell. A, Calibration steps of $10 \mathrm{mV}$ each. B, Activity recorded before the addition of the drug. C, Six minutes after the addition of tetramisole $10 \mu \mathrm{g} / \mathrm{ml}$. Records $\mathrm{D}, \mathrm{E}$ and $\mathrm{F}$ were obtained 8,9 and 10 min after the addition of the drug. The length of the horizontal line in $F$ is equal to an interval of $150 \mathrm{~ms}$. 


\section{Effects of tetramisole and acetylcholine on depolarized Ascaris muscle}

Evans, Schild \& Thesleff (1958) found that acetylcholine can in some conditions produce contractions of mammalian smooth muscle which do not depend on changes in membrane potential because it operates on preparations completely depolarized by external potassium. In skeletal muscle, contractures can be produced by caffeine that are also independent of changes in membrane potential (Axelsson \& Thesleff, 1958 ; Lüttgan \& Oetliker, 1968). To find out whether the contracture caused by tetramisole is the result of membrane depolarization or whether the drug can produce a contraction independent of changes in membrane potential, we tested the effects of tetramisole on preparations immersed in a $50 \mathrm{~mm} \mathrm{~K} \mathrm{~K}^{+}$solution. In agreement with the observations of Del Castillo, De Mello \& Morales (1964) the resting potential in this solution was $3 \pm 1 \mathrm{mV}(n=30)$. When tetramisole $(30 \mu \mathrm{g} /$ $\mathrm{ml}$ ) was added to the bath a contracture was produced. The characteristics of the contractures and the doses of tetramisole necessary to produce them were the same in the $3 \mathrm{mM} \mathrm{K}^{+}$solution and in the $50 \mathrm{mM} \mathrm{K}^{+}$solution. Acetylcholine also produced contractures of Ascaris muscle immersed in a $50 \mathrm{~mm} \mathrm{~K}+$ solution. However, the threshold concentration of the drug was $200 \mu \mathrm{g} / \mathrm{ml}$, or about 100 times larger than the concentrations required to produce an effect on muscles immersed in $3 \mathrm{mM} \mathrm{K}^{+}$solutions.

\section{Discussion}

The present results show that the paralysis of Ascaris caused by tetramisole is the result of a sustained contracture of the somatic muscles of the worm. It is unlikely that this contracture results from acetylcholine release by nerve endings because it is not blocked by curare.

Concomitant with the increase in tension, tetramisole reduced the membrane potential of the muscle cell bellies. It could be presumed that the tetramisole contracture is triggered by this reduction of resting potential. However, the experiments in depolarized muscle show that the drug can cause contracture without changing the resting potential. On the other hand, doses of acetylcholine that produced maximal effects in Ascaris muscle immersed in $3 \mathrm{~mm} \mathrm{~K} \mathrm{~K}^{+}$solution were without effect on depolarized muscle. It was necessary to increase the acetylcholine concentration several times to obtain a response. Depolarization and increase in spike frequency initiate the contractions caused by acetylcholine concentrations between 2 and $200 \mu \mathrm{g} / \mathrm{ml}$, while higher doses of ACh can produce the membrane permeability changes that lead to contraction independently of any membrane potential changes.

We thank Dr. L. Platas, from Laboratorios Columbia, S.A., for the gift of the tetramisole used in these experiments.

\section{REFERENCES}

AXelsson, J. \& Thesleff, S. (1958). Activation of the contractile mechanism in striated muscle. Acta physiol. scand., 44, 55-66.

ChaiA, G. \& Cunha, A. S. (1968). Terapeutica da ascariase com o tetramisole. Rev. Inst. Med. trop São Paulo, 10, 109-122.

DE BeLl, J. T. (1965). A long look at neuromuscular junctions in nematodes. Q. Rev. Biol., 40, 233-251.

De Bell, J., Del Castillo, J. \& Sánchez, V. (1963). Electrophysiology of the somatic muscle cells of Ascaris lumbricoides. J. cell. comp. Physiol., 62, 159-177. 
Del Castullo, J., De Mello, W. C. \& Morales, T. (1963). The physiological role of acetylcholine in the neuromuscular system of Ascaris lumbricoides. Archs int. Physiol., 71, 741-757.

Del Castillo, J., De Mello, W. C. \& Morales, T. (1964). Influence of some ions on the membrane potential of Ascaris muscle. J. gen. Physiol., 48, 129-140.

Evans, D. H. L., Schild, H. O. \& TheslefF, S. (1958). Effects of drugs on depolarized plain muscle. J. Physiol., Lond., 143, 474-485.

Goodwin, L. G. (1958). A method for recording the effects of anthelmintics on the movements of Ascaris lumbricoides. Br.J. Pharmac. Chemother., 13, 197-201.

Goodwin, L. G. \& VAUGHAN WLILIAMs, E. M. (1963). Inhibition and neuromuscular paralysis in Ascaris lumbricoides. J. Physiol., Lond., 168, 857-871.

LUTTGAN, H. C. \& OETLIKER, H. (1968). The action of caffeine on the activation of the contractile mechanism in striated muscle fibres. J. Physiol., Lond., 194, 51-74.

Thienpont, D., Vanaparius, O. F. J., Raeymaekers, A. H. M., Vandenbert, J., Demoen, P. J. A., AllewiJn, F. T. N., MARsboom, R. P. H., Niemgeers, C. J. E., Schellekens, K. H. L. \& JANSSEN, A. J. (1966). Tetramisole (R8299) a new, potent broad spectrum anthelmintic. Nature, Lond., 209, 1084-1086.

(Received October 3, 1969) 